\title{
Pre-Implementation Perceptions Among Teachers on the Use of Ecological Sanitation and Application of Human Urine as Fertilizer
}

\author{
Govinda Prasad Devkota ${ }^{1}$, Sheri Lee Bastien ${ }^{2,3}$, Petter D. Jenssen ${ }^{4}$, Manoj K. Pandey ${ }^{4}$, Bhimsen Devkota ${ }^{5}$ \& \\ Shyam Krishna Maharjan ${ }^{6}$ \\ ${ }^{1}$ Graduate School of Education, Tribhuvan University, Nepal \\ ${ }^{2}$ Department of Public Health Science, Norwegian University of Life Sciences, Norway \\ ${ }^{3}$ Cumming School of Medicine, University of Calgary, Canada \\ ${ }^{4}$ Faculty of Environmental Sciences and Natural Resource Management, Norwegian University of Life Sciences, \\ Norway \\ ${ }^{5}$ Lead Project Coordinator, NORHED/Rupantaran project, Tribhuvan University, Nepal \\ ${ }^{6}$ Central Department of Education, Tribhuvan University, Nepal \\ Correspondence: Govinda Prasad Devkota, Department of Health and Physical Education, Mahendra Ratna \\ Campus, Tribhuvan University, Kathmandu, Nepal. E-mail: devkotagovinda11@gmail.com
}

Received: May 19, $2020 \quad$ Accepted: July 10, $2020 \quad$ Online Published: October 23, 2020

doi:10.5539/ies.v13n11p55 URL: https://doi.org/10.5539/ies.v13n11p55

\begin{abstract}
Although human urine contains nutrients for plant growth, very few community schools in Nepal use a urine diversion dry toilet (UDDT) and apply the human urine as fertilizer in their school garden. Using human urine in agriculture reduces the use of chemical fertilizers, thus saving the expenditure associated with it. Application of human urine improves the soil fertility and may contribute to increased food security among school children if the school can supply the canteen with food for mid-day meals. This study adopted a Participatory Action Research (PAR) approach in order to understand stakeholder perspectives and involve them in the planning and implementation of urine diverting toilets. The data for this study were collected from five teachers' focus group discussions. This paper presents teachers' perceptions of the urine diversion dry toilet system and use of human urine as a fertilizer for the school garden. Only a few teachers accepted that human urine could be used as fertilizer, however, they were not willing to use it on their crops since it was considered impure. Due to a perceived bad odor and the uncomfortable sitting position on the UDDT, particularly for females, teachers disliked this toilet and they felt using urine as fertilizer was unnecessary. One of the key lessons drawn from the study is that schools, in collaboration with local governments, should employ participatory approaches to understanding and engaging local stakeholders, including teachers, to minimize negative perceptions prior to the application of human urine as fertilizer in the school garden.
\end{abstract}

Keywords: Nepal, participatory action research, school garden, urine diversion dry toilet

\section{Introduction}

Ecological sanitation (Eco-san) system is one sanitation method that can be efficient, sustainable, and cost-effective in making use of human waste. The system separates the human urine from the faeces and reuses it for agricultural purposes (Haq \& Cambridge, 2012). It is a viable natural alternative to chemical fertilizers that could enrich the microorganisms in the soil. Human urine is naturally rich in nitrogen, potassium, and phosphorus. Crops and vegetables fertilized with human urine were found to be 10 percent larger than those grown with conventional fertilizer (Effebi, Ballet, Seka, Baya, \& N'takpe, 2019). So, the Eco-san toilet is the best solution for environmental sanitation and the resource retrieval of organic matter for crops and vegetables.

Eco-san systems which use human waste hold the potential to improve the sanitary situation in an efficient way (Pradhan, Piya, \& Heinonen-Tanski, 2011). Since the system is cost-effective to construct and environmentally safe to use, it may decrease the risk of diseases (Mayo \& Mubarak, 2015), and also could increase perceptions of food security (Ersson \& King, 2019). Poor sanitation causes negative effects on the environment, the economy, and well-being (Chariar \& Ramesh Sakthived, 2011). This is a common issue in low-income countries like Nepal 
(McMichael, 2019), where a large proportion of people still lack access to improved sanitation (Rajbhandari, 2008). Efforts to improve this situation have been taken, but still, many Nepali people lack access to improved sanitation (Baum, Luh, \& Bartram, 2013). The Sustainable Development Goals (SDGs) 2016-2030 focus on the need for new working methods, incorporating the three areas of sustainable development which include economic, environmental, and social sustainability. Nepal has achieved the Millennium Development Goals (MDGs) target of halving the proportion of residents who are without access to improved sanitation and who do not have sustainable access to basic drinking water. The population with access to improved sources of drinking water increased from 46 percent in 1990 to 81 percent in 2015. The proposed targets for SDG 6 are to ensure that 95 percent of households have improved sanitation facilities and that 98 percent of the population use a toilet (WHO/UNICEF, 2017).

Despite growing awareness of persistent gaps in sanitation access and the associated implications for society, progress to ensure access and use of improved sanitation has lagged behind the progress of other development challenges, particularly in rural areas (Langergraber \& Muellegger, 2005). A recent report by the World Health Organization (WHO) and the United Nations Children's Fund (UNICEF) Joint Monitoring Program (JMP) states that 39 percent of the global population (2.9 billion people) use safely managed sanitation services, where human excreta are safely disposed of and treated off-site (WHO/UNICEF, 2017).

Eco-san toilets are an innovation that can be efficient, sustainable, and cost-effective in utilizing human excreta as fertilizer. In Eco-san system, urine and faeces separates from commods/pan. Technically, a raised area in front of Eco-san pan/ commode that drains urine into a different tank/ chamber while faeces gets deposited in the back half of the pan and storage into the other chamber. Similarly, only urine can be deposited through urinal and used as fertilizer by dilution of certain amount of water. For this, urine need to be collected in the chamber stored it for 15-20 days to destroy micro-organisms (Devkota, Pandey, \& Maharjan, 2019). Eco-san is beneficial because the system is safer hygienically, due to the access to improved sanitation and the recycling of valuable nutrients as fertilizer (Werner, Panesar, Rüd, \& Olt, 2009). By creating a closed-loop (Uddin et al., 2019), Eco-san could be improved and could lead to a more stable agriculture process in low and middle-income countries like Nepal (Rajbhandari, 2008). Phosphorus dependency in food production can also improve the sanitation situation (Werner et al., 2009). The Eco-san technology is appropriate for schools since it is cost-effective, environment-friendly, and provides a rich source of nutrients for crops and vegetables (Mkhize, Taylor, Udert, Gounden, \& Buckley, 2017).

Though human urine consists of nutrient byproducts and holds the potential to enhance livelihoods when utilizing it as a fertilizer, there is still a lack of integrated curriculum that includes using the Eco-san toilet system as a sanitation innovation in the school education system in Nepal. Despite government priority, a study done by Adhikari indicates that the Eco-san toilets are not being constructed throughout the community schools in Nepal (Adhikari, 2012). As a result community people, teachers, as well as students may not know about the Eco-san toilet and its importance (WHO/UNICEF, 2017). The unavailability of Eco-san toilets may be a lost opportunity in using agro-products in the school garden. The possibilities of using compost made from toilets and human urine to grow greater quantities of vegetables and cereals have huge practical applications within the schools themselves (Sene, Hijikata, Ushijima, \& Funamizu, 2019).

In line with the SDGs, this study under the Norwegian Programme for Capacity Development in Higher Education and Research for Development (NORHED)/Rupantaran Project aims to improve the quality of teaching and learning through innovative, transformative, and contextualized pedagogical strategies at the basic level (grades 1-8). The project is being executed in the Chitwan and Nawalparasi Districts of Nepal. This study focuses on a wide range of capacity building and development issues related to the Eco-san toilet, handwashing with soap, and the use of human urine as fertilizer in the school garden.

The study used the Diffusion of Innovation Theory (DOI) developed by Evert Rogers which has been used for the past 55 years (Rogers, 2010). The diffusion of innovation theory is a behavior change theory, which may be used to explain people's perceptions and actions. It is an important theory used to explore the reasons why individuals adopt or do not adopt innovations. This theory is relevant for this study due to the focus of adoption and behavior change of the Ecosan system, a new technology for Nepal.

\section{Methods}

The PAR approach used in this study focused on acquiring a comprehensive understanding of stakeholder perspectives about the Eco-san technology and the possibility of applying human urine as fertilizer on the school garden. Teachers' perceptions of the Eco-san technology and the application of human urine as fertilizer within the first PAR cycle were obtained through focused group discussions. The study also explored participants' motivation to adopt Eco-san technology and urine application in their school garden. The study was conducted in five 
community schools located in Chitwan district in the southwestern part of Nepal. The study focused on the use of the Eco-san toilet in transforming the hygiene and sanitation behaviors of students. The schools and the teacher participants were selected purposively and were based on the Norwegian Agency for Development Cooperation (NORAD) funded Rupantaran project's guidelines (Note 1). Five focus group discussions (FGDs) with 53 participants (31 female and 22 male) were conducted as part of this study.

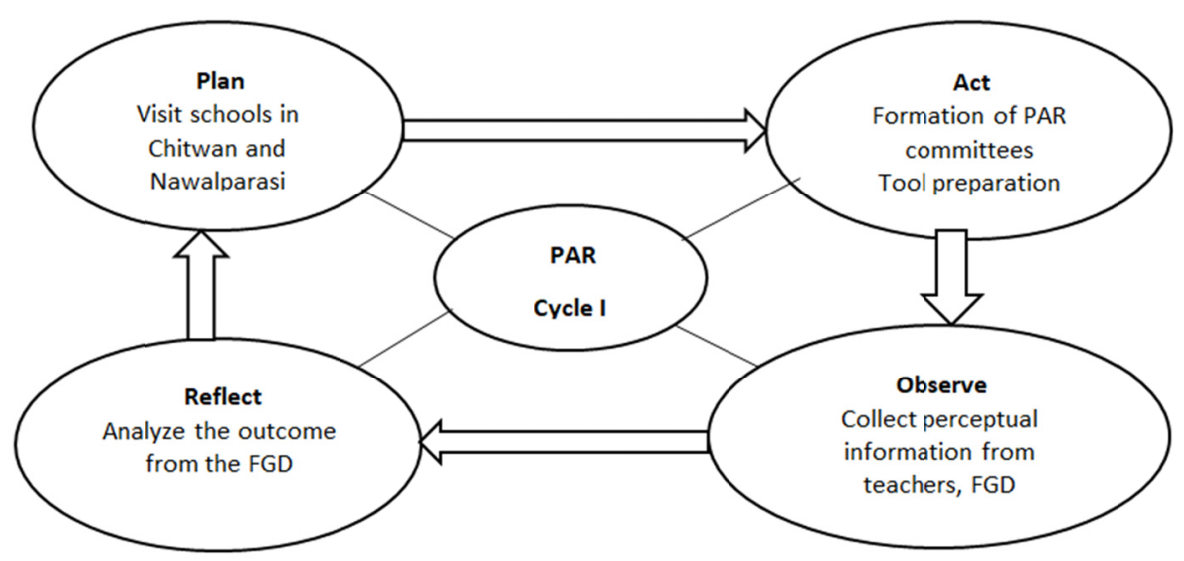

Figure 1. Process of the first cycle in PAR (Source: Field insights)

This study was conducted in three PAR cycles progressing through the chain of plan-act-reflect in process (Kemmis, McTaggart, \& Nixon, 2013). The first cycle took place during four weeks in July 2017 when the researcher worked with the schools to assess perceptions on the Eco-san system, as well as the possibilities for implementing it in the project schools.

The data for this manuscript is based on research participants' knowledge and perceptions before the intervention of the Ecosan toilet. However, according to PAR guidelines (Kemmis et al., 2013), the PAR committee was formed in each project school and were actively engaged in collaboratively preparing the FGD discussion guides. In a post-data collection workshop, the PAR and School Management Committee (SMC) members attended the educational session which used visual aids on the Ecological Sanitation toilet and urine application in crops, vegetables, and fruits. Moreover, the objectives of the study were discussed, including the ethical aspects, with the PAR committee and research participants before starting the FGD. It was reported that they were not aware of the Eco-san toilet at the schools.

In PAR, perception is vital for the process and thus, the power relationship between the researcher and the learning communities is equalized as all voices are included (Ritchie, Lewis, Nicholls, \& Ormston, 2013). To empower the participants is more central (Green \& Thorogood, 2018), and their actions and reflections (McNiff, 2013) have been a central focus linking pedagogy to Eco-san toilets.

In the first cycle of PAR, the researcher encouraged the participants to express their perceptions of Eco-san. The purpose was to acquire knowledge concerning the possibility of implementing such a system. In the first cycle of the study, FGD was used to gain an understanding of the perception and views of the teachers. Hence, the first cycle emphasized collecting perceptions and views on the Eco-san as well as on the application of human urine as fertilizer in the school garden.

\subsection{Focus Group Discussions}

The FGD method was selected since it helps in gaining insight into diverse views and perspectives among a wide range of teachers. FGDs are also a relevant method in PAR in the school setting and are a common way of collecting and sharing information of different kinds (Green \& Thorogood, 2018). Six FGDs were conducted consisting of 7-10 teacher participants in five community schools who were willing to share their perspectives about the Eco-san system, and who had been teaching health, population, and environment education. The discussion was based on the FGD guidelines and conducted in the Nepali language. The themes of the guidelines were: (a) awareness/knowledge of the Eco-san toilet; (b) potential acceptance of the Eco-san toilet; (c) perceptions towards Eco-san toilet use; (d) cultural perspectives on Eco-san toilets; (e) gender perceptions of Eco-san toilets; and (f) views on the application of human urine as fertilizer in the school garden. The FGD lasted between 50-90 
minutes (including the introduction of the study objectives and ethical consideration). The group was intended to be gender-balanced, but the different groups had different gender representation as depicted in Table 1.

Table 1. Number of participants by schools

\begin{tabular}{cccccc}
\hline \multirow{2}{*}{ School code } & School intervention type & \multicolumn{2}{c}{ Gender/Groups } & \multirow{2}{*}{ Total Participants } & \multirow{2}{*}{ Total time (Minutes) } \\
\cline { 3 - 4 } & Male & Female & & \\
\hline 01 & Action School & 4 & 6 & 10 & 90 \\
02 & Reference school & 3 & 9 & 12 & 90 \\
03 & Reference school & 4 & 6 & 10 & 80 \\
04 & Reference school & 6 & 6 & 12 & 90 \\
05 & Reference school & 5 & 4 & 09 & 70 \\
Total & & 28 & 36 & 64 & \\
\hline
\end{tabular}

\subsection{Data Analysis}

The FGDs were audio-taped with informed consent from the participants. The audiotapes were transcribed into Nepali first and then into English. Data were analyzed using a thematic content analysis approach (Green \& Thorogood, 2018). This method is commonly used in qualitative studies and has been used with an inductive approach. Accordingly, themes and categories were developed and emerged from the transcribed materials. The analysis was done in different stages. First, open coding was completed, which included reading and re-reading of the empirical data and summarizing the content by making notes on the material. This created an initial coding framework (Green \& Thorogood, 2018) with several categories. In the second stage, the collected material and the created categories were reduced based on the outcome from the first step. Similar categories emerged into one theme and the material was reduced. Thus, the reduction was further refined based on the analytical and theoretical approach (Diffusion of Innovation). In the next step, all the remaining categories were color-coded, and the transcribed material was read through again for expressions and thoughts. Categories were marked with the color corresponding to the category and were further merged into a final analyzing framework (Burnard, Gill, Stewart, Treasure, \& Chadwick, 2008). After the organization of the material using this process, the findings were presented.

\subsection{Ethical Consideration}

Before the fieldwork, ethical approval was obtained by the Nepal Health Research Council (NHRC) with the reference number 1960/2019, Ministry of Health (MoH), and Government of Nepal (GoN). Written informed consent was obtained from the head teachers and participating teachers after the purpose of the study was explained to them. All participants signed consent forms for recording their voices. The confidentiality of the participants was maintained by assigning a unique code to each of the participants. No names were exposed in the paper.

\section{Findings}

The themes that emerged from the data analysis such as awareness and knowledge, perceptions, and potential acceptance relating to the use of the Eco-san toilet, and application of human urine as fertilizer, were the key themes. Awareness and knowledge of the Ecosan system was defined as having been exposed to information from friends, YouTube videos, and radio programs (Tumwebaze \& Niwagaba, 2011). Potential acceptance here meant the willingness to incorporate the Eco-san and the application of human urine in school gardens. Similarly, perceptions in this study refer to one's positive or negative judgment (Acharya, Devkota, \& Dhakal, 2020) with regards to the use of the Eco-san toilet and the application of human urine as fertilizer. This was measured using an indirect interpretive technique which focused on understanding how participants stated they felt, and what other people said about it.

\subsection{Awareness of the Eco-San Toilet}

The majority of the participating teachers said they had not heard of the Eco-san toilet. This highlights the fact that information on the Eco-san system had not reached the majority of teachers. The quote below illustrates this:

We lack knowledge of the Eco-san toilet. No related course and information were mentioned in the school curriculum and no Municipality or wards have given us information on the Eco-san. Even radio programs relating to the use of human urine as fertilizer have not been found. We learned very little about the Eco-san from the internet and youtube. (Male teacher, FGD 1) 
No instruction whatsoever has been done and there has been no formal course to promote the Eco-san. (Female teacher, FGD 3)

The above quotes reveal that a low level of awareness about the Eco-san can be attributed to a lack of related contents in the school curriculum, lack of an educational program conducted by the local government on human waste, and also lack of access to radio programs and community campaigns.

\subsection{Acceptance of Eco-San Toilet}

The study findings show that the research participants foresee multiple benefits of the Eco-san toilet. Some of the participants identify economic and sanitary benefits as an important aspect when valuing and accepting new ideas. Similarly, they see organic manure as healthier for both the environment and human beings. Thus, the idea of Eco-san innovation seems to be feasible to implement in the community. However, a few research participants expressed the opinion that Eco-san and the application of human urine were potentially problematic, because they perceived urine as unclean or impure, and therefore they did not value it's use as a fertilizer. Furthermore, the FGD participants were unsure about the technical functionality of the Eco-san and did not understand how diversion of urine and feces, transportation of the urine to the garden or fields, management of bad odor, and handling of sanitary problems were accomplished.

Although the participants were less willing to accept the Eco-san toilet, a few teachers had heard about this innovation from media and they accepted its potential use. They showed greater awareness about the importance of using such toilets and applying human urine as fertilizer in the school garden as well as on their crops and fields.

It is good to use the Eco-san toilet because human urine can be used as fertilizer with this technology. (Male teacher, FGD 5,)

We do not consider using the Eco-san a priority because no one is prepared to empty it and distribute it to the crops. We feel uneasy doing so. (Female teacher, FGD 2)

Sadly, our school does not have gardens anymore, and we are not even interested to have them. I do not think students and teachers would apply human urine on their crops. (Female teacher, FGD 4)

Although the participants generally did not accept the Eco-san toilet, the male participants were more positive and they showed greater awareness as to why it was needed compared to the female participants, who often compared the Eco-san toilet to the ventilated improved pit latrine (VIP). The statement above reveals that touching human urine is considered to be a taboo in the school. Handling human urine and applying it on the school garden was not easily accepted in school.

\subsection{Perception on Use of Eco-San Toilet}

Most of the participants did not prefer the Eco-san toilet. They reported that they did not like the Eco-san toilet as they perceived it to be unhygienic, having a bad odor, unhealthy, and too technical.

So far, we know, the Eco-san toilet is too technical, and has a high chance to store feces in the pan causing a bad smell. It is uncomfortable. There is more probability to inhale germs if we handle human urine as fertilizer. (Female teacher, FGD 4)

The flush toilet is better, obviously better because we can use water for cleaning, flushing and hand washing. (Female teacher, FGD 5)

A flushed toilet is much better because your waste is flushed away; it is not stored within the pan. (Female teacher FGD 1)

This shows a negative perception about using human urine and highlights that it is a new idea.

\subsection{Cultural Perspectives on Eco-San Toilet}

There are cultural beliefs related to handling and working with the Eco-san toilet. It is unacceptable in Nepal to handle human urine as is dictated by the norms and traditions of the Nepalese culture. The research participants believed that people should not be exposed to human urine because it is dirty and may lead to illness. So, changing a cultural belief seems to be a very difficult task. Those FGD participants who opposed the Eco-san toilet said it was not compatible with the local culture and tradition. One participant said:

Mixing ash with feces, leaving feces, and doing pee openly is against our culture. If anyone does so, God will punish them through witches and demons. (Female teacher 3)

Another participant expressed his fear thus:

According to our tradition, people don't like to eat something that has been grown in our feces and urine. 
People feel something bad. If we go to the market and say that these products are produced by using human urine, people will not buy them. (Male teacher, FGD 4)

The crops grown will not smell like feces. It is just a matter of joking. Human urine does not make food smelly, but it is more organic. (Male teacher, FGD 1)

The participants expressed concerns on how to take care of the waste from the Eco-san toilet. Proper education on the advantages of the Eco-san and technical support for using human urine without touching it helps to transform people's perception on the optimum use of the Eco-san toilet for changing human urine into a resource.

\subsection{Gender Perspectives on Eco-San Toilets}

Most of the female teachers perceived that the Eco-san toilet was not gender friendly. They thought that blood spots would be seen on the Eco-san pan when they have their menstrual period. Due to odor and an uncomfortable sitting position on the Eco-san, some female teachers disliked this toilet and they felt using urine as a resource was less important to them. They also reported that the divider of the pan passing urine and feces into different holes was not as appropriate for females when compared to males, because the distance between the urethra and anus of the female is shorter than for males. They opined that it was a bit problematic to divert urine and feces into different holes. However, a few of the female teachers thought that the Eco-san toilet could improve menstrual hygiene management (MHM) due to improved privacy and better facilities, like a closed waste bin and the possibility of washing hands with soap inside the toilet room.

The Eco-san toilet can improve menstrual hygiene management because there is privacy, better facilities for disposing of waste, and handwashing facilities inside. (Female teacher, FGD 1)

So, girls can use the Eco-san toilet during their period. This shows that the Eco-san system is seen as more useful and more preferable than the pit or other types of toilets for women and girls, as expressed in the quote below.

The menstrual discharge may clot in the Eco-san pan and is a disgusting matter. (Female teacher, FGD, 2)

The design of the Eco-san toilet pan does not provide for enough urine diversion for females. Both feces and urine may go in the same hole. (Female teacher, FGD, 3)

The Eco-san toilets improve MHM due to improved privacy and better facilities. Our basic requirements are a closed waste bin, enough space to change a menstrual pad, and the possibility of hand washing with soap inside the toilet room. (Female teacher, FGD, 4)

\subsection{Views on the Application of Human Urine as Fertilizer in the School Garden}

The majority of the FGD participants reported that they were not willing to involve themselves in the removal of the urine from the toilet or the collection of urine in a bottle or drum. But they were interested to use human urine in their school garden if there could be an automatic piping or drip irrigation (Note 2) system that does not involve handling feces and urine. Handling human waste was perceived as a matter of dignity in the school community. The quote below illustrates this point:

Emptying the urinal chamber by the teachers is impossible. The teacher's job is to teach the students and not to clean and transfer urine. The teacher is not meant to work on the toilet. We can work in the school garden using human urine as fertilizer if the auto supply/piping (Note 3) system is available, then it is ok for us. (Male teacher, FGD, 1)

A minority of teachers were positive towards using the approach of human urine as a form of agricultural fertilizer. They reported that human urine is a richer source of organic fertilizer. They stressed the only problem with the Eco-san toilets and the application of human urine was handling it. They said if the technology supports it's use without using one's hands, then they were ready to use human waste as fertilizer for growing crops. They were aware that human urine as fertilizer is better than chemical fertilizers since chemical fertilizers are seen as poisonous for both the soil and human health and can lead to disease. The quote below illustrates this point.

Chemical fertilizers are destroying our soils, and the fruits, vegetables, and crops produced using chemical fertilizer are harmful to our health. (Male teacher, FGD, 3)

Additionally, how people can be motivated to use the Eco-san toilets, the application of human urine as a good agricultural fertilizer, and the best solution for sanitation were topics raised in FGD. Almost all the participants reported that educational support is needed for raising acceptance and understanding of the Eco-san toilet. They said:

Educating students in school would be a better method of teaching awareness to their parents. So, 
knowledge regarding the use of the Eco-san toilet and its effectiveness needs to be shared with the students and they can then, teach their parents. (Male teacher, FGD, 2)

The statement above also shows that with the help of classroom pedagogy and awareness programs, the misconceptions about the Eco-san toilet and urine application on the school garden may be minimized. Further, the solution to changing perceptions and behaviors about the Eco-san toilet is through classroom pedagogy and by constructing a model toilet in the school.

\section{Discussion}

The findings of this study show that the majority of the research participants were not aware of Eco-sandue to a lack of related education in schools. Therefore, the community school teachers do not recognize its benefits. A minority of teachers accessed the information on Eco-san toilets and the value of human urine through mass media such as radio, internet, YouTube, neighbors, and friends. The findings correspond with a study in Uganda which reported that poor advocacy concerning Eco-san, and a lack of knowledge were the causes for a high prevalence of misconceptions existing in community schools (Trimmer et al., 2016). Several studies correspond to the findings of this study about using human urine as fertilizer on crops. It was also found that research participants who knew about likely positive outcomes of applying human urine as fertilizer on crops were distinctively more willing to apply it on their crops than those who did not know about it. Moreover, they did not feel it was unhygienic to eat food products that had been grown using human urine as fertilizer (Karak \& Bhattacharyya, 2011; Kocatürk \& Baykal, 2012; Mariwah \& Drangert, 2011) ever, after using the Information Education Communication (IEC) materials to educate participants, installing an Eco-san toilet in the school, and more training, participants' knowledge increased.(Trimmer et al., 2016). Similarly, these findings contrast with the study conducted in Uganda on Eco-san system acceptance, knowledge, and beliefs and practices in community settings. The majority of the participants had some knowledge about the Eco-san system through massive communication channels. Furthermore, Eco-san was included in the national curriculum of Uganda that resulted in school children learning about its advantages (Tumwebaze \& Niwagaba, 2011).

This study assessed the willingness of participants to use the Eco-san toilet, handle it, and use human urine as a fertilizer in the school garden. The findings suggest that many participants were not willing to handle and remove the urine from the toilets, saying that it would compromise their dignity. However, a study carried out in the U.S. showed that by using a public education programme to promote the use of the Eco-san toilet and subsequent human waste recycling, social benefits could be achieved, such as reduced water and chemical fertilizer use, reduced greenhouse gas emissions, and collection of micropollutants at their source (Lamichhane \& Babcock Jr, 2013). A similar study conducted in Kenya found that most of the study participants overcame social and cultural barriers through public awareness and acceptance of Eco-san toilets. They were, now, using human urine as fertilizer on their farms. Moreover, they recommended the practice to a wider community (Uddin, Muhandiki, Fukuda, Nakamura, \& Sakai, 2012). Likewise, a similar study conducted in Indonesia (Mariwah \& Drangert, 2011) found that Indonesians accepted Eco-san toilets because of the perceived environmental friendliness and the fertilizer value. Some of the participants thought the possibility that the innovation used in the Eco-san system could be of value. They noted the advantage of using the Eco-san toilet and applying urine as fertilizer in school gardens over other types of toilets and chemical fertilizers. They also reported the economic benefits the Eco-san toilet can achieve in valuing and accepting Eco-san innovations. However, most of the research participants expressed that they do not see the Eco-san toilet and human urine application as a potential fertilizer.

In this study, we explored the perceptions of the community schoolteachers on the Eco-san toilet and application of human urine as a fertilizer. The majority of teachers often mentioned their negative perceptions as being more technical to use, uncomfortable, bad-smelling, and unhealthy. The findings contrast with those from a study in Uganda (Tumwebaze \& Niwagaba, 2011) in which the majority of participants had positive sentiments on the use of the Eco-san toilet and urine application as fertilizer. However, a minority of teachers reported that they would be willing to eat foods fertilized by human urine because they thought that human urine was not a source of contamination if treated properly (Takahashi, Sakai, \& Ahmed, 2016).

A study evaluating the sanitary improvements and benefits of the Eco-san toilet (Trimmer et al., 2016) showed that demonstration facilities can improve stakeholders' views of Eco-san toilets; however, it is uncertain whether these facilities should be located at households or institutions. In some cases, people desired to buy and use Eco-san technology after they observed its use in a friend's home. Also, participants blamed a lack of education on how to use and maintain the toilet. They questioned the long-term economic and hygienic value of the Eco-san toilet in schools. Farming practices, awareness of the Eco-san toilet, and the fertilizer value of urine were shown by the researchers (Sharda \& Shinjo, 2017). Shonde (2016) argued that the application and acceptability for Eco-san 
toilets in the school community helped in solving the existing and emerging sanitation problems (Shonde, 2016).

The findings correspond with a study conducted in Uganda (Tumwebaze \& Niwagaba, 2011) that showed farmers may prefer to build an Eco-san toilet because of its value in promoting agricultural production. Another study regarding the perception of the Eco-san system (O'Keefe, Messmer, Lüthi, \& Tobias, 2015) found that people's desire for improvements in sanitation, and the way they evaluate a new toilet is still in development. Their social processes and constraints also affect their decisions. This study further claimed that people liked the Eco-san toilet. Also, they expect large health benefits from it, and it complies with cultural norms. Another study (Karak \& Bhattacharyya, 2011) found that fermented human urine from the Eco-san toilet facility was used as a natural fertilizer.

The findings of this study showed the system as complicated and needing more participatory teaching for correct use of Eco-san toilet and use human urine as fertilizer. However, the research participants were willing to learn more about Eco-san. Thus, the possibility of constructing a pilot Eco-san toilet for demonstration purposes was regarded as important. It was often claimed that people were initially reluctant to talk about human waste as they considered this a personal matter (Nawab, Nyborg, Esser, \& Jenssen, 2006). Perceptions about health hazards and people's revulsion towards human urine varies between cultures (Duncker, Matsebe, \& Moilwa, 2007). A study in Honduras also found a close linkage between poverty and access to basic sanitation (Mariwah \& Drangert, 2011). Similarly, this finding corresponds with a study conducted in Pakistan on cultural preferences in designing Eco-san systems in northwest Frontier Province which found that, based on religious and cultural orientation, water-based sanitation was preferred over the Eco-san toilet and use of human urine as fertilizer on crops (Nawab et al., 2006).

Sanitation and menstrual hygiene are considered to be a very private matter for females in most cultures. Women are most affected by inadequate sanitation because of menstruation and pregnancy. There is often a sense of shame related to toilet visits, especially for women (Elledge et al., 2018). Another study conducted in Romania (Samwel, Gabizon, Wolters, \& Wolters, 2006; Samwel et al., 2006) found that women are not allowed to use common toilets during menstruation. This causes shame which makes their life more difficult. However, experience from Zimbabwe indicated that women in rural areas prefer the Eco-san toilet and so, they built it closer to their houses (Hannan \& Andersson, 2002; Kaur et al., 2018).

This study reveals some practical and evidence-based insights for further development of the project using Eco-san and the application of human urine as fertilizer. It recommends intensive awareness campaigns and advocacy to remove negative attitudes towards ecological sanitation toilets, training in the toilet operation, regular reviews and check-ups by authorities, and further studies in wider areas in Nepal. As it is the very beginning phase of the PAR project, the voices and concerns from different interest groups are supportive of making participatory plans and actions. The idea of the Eco-san toilet and application of human urine for agriculture purposes is a new and culturally sensitive issue, so it seems further consideration should be made by school and community stakeholders to become familiar with the basic concepts and benefits of the Eco-san toilet as a teaching and learning resource in schools. The participants in the FGDs saw the relative advantages with the Eco-san system. The current sanitation system and management of human waste are described as unsatisfactory and hence participants see the advantages that Eco-san can bring as a solution for environmental pollution. They also understood the economic benefits that Eco-san could bring such as increasing food production with the use of human urine as fertilizer. At the beginning of the discussion about the application of human urine as agricultural fertilizer there was a lot of laughter among the participants, signaling an expression of underlying negative interpretation. However, dualistic opinions were expressed; the participants saw that organic matter in the human urine meant access to free and nutritious fertilizer. Therefore, the potential for the Eco-san idea could expand in the present with needed educational and demonstrational support.

\section{Limitations}

Some female teachers had experience using Eco-san toilets in their birthplace (Maiti). Such experiences influenced the variability of responses in FGD regarding the Eco-san toilet and application of human urine as fertilizer in their crops. Since this is a baseline study, their reflections on use of the Eco-san toilet have not been incorporated.

\section{Conclusion and Implications}

The study revealed that the majority of the research participants expressed a low willingness to accept the Eco-san toilet. Though half of the participants knew the value of human urine as a better fertilizer, they still regarded it as waste and as unhealthy. Eco-san technology has not been introduced and implemented as a part of teaching and learning in the school curriculum to date. Now, newly drafted curriculum by the Curriculum Development Centre under the Ministry of Education, Nepal has incorporated the general concept of Eco-san in terms of its meaning and application. Teachers' participation, with the provision of education, about the Eco-san toilets and the 
application of human urine as fertilizer are important strategies in changing perceptions in community schools in Nepal.

The emphasis needs to be on teachers' participation and on education to counter perceptions about applying human urine on agricultural products. This will help improve acceptance and use of the Eco-san toilets. Strategies for broadening the issue to all community schools should preferably, include teachers, students, and other stakeholders such as the municipality in the area. That would elicit more holistic and efficient ways of problem-solving in the intervention program.

Local Government has to initiate capacity development programs at schools for the promotion of Eco-san in terms of skills for education and construction of the toilets. There is a need to promote appropriate Eco-san demonstration toilets which are usable for the schools. To achieve this, the concerned stakeholders need to find some way to minimize the structural and functional challenges arising in the process. As this study suggests, the school has to connect the curriculum in everyday teaching and learning with the Eco-san toilet and school gardening activities. Likewise, the school needs to introduce curriculum and outreach sessions to educate parents about the use and benefits of the Eco-san toilet. Further, the construction of the Eco-san toilet needs to be both gender and age appropriate for the school students.

\section{Acknowledgments}

We would like to extend thanks to all the teachers who participated in the study. Thanks go to NORAD funded NORHED/Rupantaran Project (2016-2021), agreement number 2016Q2A04, for providing financial support to this study, which is jointly implemented in Nepal by Tribhuvan University (TU), Kathmandu University (KU) and Norwegian University of Life Sciences (NMBU). We would like to thank to the University Grants Commission, Nepal for the support to publish this paper.

\section{References}

Acharya, K. P., Devkota, G. P., \& Dhakal, K. P. (2020). Small Change Is Beautiful: Exploring Possibilities of Eco-San on School Garden for Transformative Pedagogy. Higher Education Studies, 10(2), 122-132. https://doi.org/10.5539/hes.v10n2p122

Adhikari, K. (2012). Sanitation in Nepal:... Past, Present and Future. Kunti Bhoomi Memorial Trust.

Baum, R., Luh, J., \& Bartram, J. (2013). Sanitation: a global estimate of sewerage connections without treatment and the resulting impact on MDG progress. Environmental science \& technology, 47(4), 1994-2000. https://doi.org/10.1021/es304284f

Burnard, P., Gill, P., Stewart, K., Treasure, E., \& Chadwick, B. (2008). Analysing and presenting qualitative data. British dental journal, 204(8), 429. https://doi.org/10.1038/sj.bdj.2008.292

Chariar, V., \& Ramesh Sakthived, S. (2011). Ecological Sanitation: Practitioner's Hand Book. Govt. of India and UNICEF, 192.

Devkota, G. P., Pandey, M. K., \& Maharjan, S. K. (2019). Urine Diversion Dry Toilet: A Narrative Review on Gaps and Problems and its Transformation. European Journal of Behavioral Sciences, 2(3), 10-19. https://doi.org/10.33422/ejbs.v2i3.151

Duncker, L., Matsebe, G., \& Moilwa, N. (2007). The social/cultural acceptability of using human excreta (faeces and urine) for food production in rural settlements in South Africa. Citeseer.

Effebi, K., Ballet, G., Seka, M., Baya, D., \& N'takpe, B. (2019). Physicochemical and microbiological characterization of human faeces and urine from composting toilets in Abidjan, Côte d'Ivoire. Environmental technology, 40(3), 293-301. https://doi.org/10.1080/09593330.2017.1387610

Elledge, M. F., Muralidharan, A., Parker, A., Ravndal, K. T., Siddiqui, M., Toolaram, A. P., \& Woodward, K. P. (2018). Menstrual hygiene management and waste disposal in low and middle income Countries-A review of the literature. International journal of environmental research and public health, 15(11), 2562. https://doi.org/10.3390/ijerph15112562

Ersson, O., \& King, K. (2019). The Kailash Ecovillage project converting human excreta into organic foodstuffs and sanitized compost using new international building codes for compost toilet and urine diversion systems. Blue Green Systems, 1(1), 33-54. https://doi.org/10.2166/bgs.2019.192

Green, J., \& Thorogood, N. (2018). Qualitative methods for health research. Sage.

Hannan, C., \& Andersson, I. (2002). Gender perspectives on ecological sanitation. Stockholm, Ecosanres. Retrieved from https:/www.ircwash.org/sites/default/files/Hannan-2002-Gender.pdf 
Haq, G., \& Cambridge, H. (2012). Exploiting the co-benefits of ecological sanitation. Curr Option Environ Sustain, 4, 431-435. https://doi.org/10.1016/j.cosust.2012.09.002

Karak, T., \& Bhattacharyya, P. (2011). Human urine as a source of alternative natural fertilizer in agriculture: A flight of fancy or an achievable reality. Resources, conservation and recycling, 55(4), 400-408. https://doi.org/10.1016/j.resconrec.2010.12.008

Kaur, R., Kaur, K., \& Kaur, R. (2018). Menstrual hygiene, management, and waste disposal: Practices and challenges faced by girls/women of developing countries. Journal of environmental and public health, 2018. https://doi.org/10.1155/2018/1730964

Kemmis, S., McTaggart, R., \& Nixon, R. (2013). The action research planner: Doing critical participatory action research. Springer Science \& Business Media. https://doi.org/10.1007/978-981-4560-67-2

Kocatürk, N. P., \& Baykal, B. B. (2012). Recovery of plant nutrients from dilute solutions of human urine and preliminary investigations on pot trials. Clean-Soil, Air, Water, 40(5), 538-544. https://doi.org/10.1002/clen.201100193

Lamichhane, K. M., \& Babcock Jr., R. W. (2013). Survey of attitudes and perceptions of urine-diverting toilets and human waste recycling in Hawaii. Science of the total environment, 443, 749-756. https://doi.org/10.1016/j.scitotenv.2012.11.039

Langergraber, G., \& Muellegger, E. (2005). Ecological Sanitation-a way to solve global sanitation problems? Environment international, 31(3), 433-444. https://doi.org/10.1016/j.envint.2004.08.006

Mariwah, S., \& Drangert, J.-O. (2011). Community perceptions of human excreta as fertilizer in peri-urban agriculture in Ghana. Waste Management \& Research, 29(8), 815-822. https://doi.org/10.1177/0734242X10390073

Mayo, A. W., \& Mubarak, T. (2015). Challenges of adoption of urine-diversion dry toilets technology as sanitation option by coastal communities of Mkuranga District in Tanzania. African Journal of Environmental Science and Technology, 9(5), 482-492. https://doi.org/10.5897/AJEST2014.1779

McMichael, C. (2019). Water, sanitation and hygiene (WASH) in schools in low-income countries: A review of evidence of impact. International journal of environmental research and public health, 16(3), 359. https://doi.org/10.3390/ijerph16030359

McNiff, J. (2013). Action research: Principles and practice. Routledge. https://doi.org/10.5539/hes.v10n2p122

Mkhize, N., Taylor, M., Udert, K. M., Gounden, T. G., \& Buckley, C. A. (2017). Urine diversion dry toilets in eThekwini Municipality, South Africa: acceptance, use and maintenance through users' eyes. Journal of Water, Sanitation and Hygiene for Development, 7(1), 111-120. https://doi.org/10.2166/washdev.2017.079

Nawab, B., Nyborg, I. L., Esser, K. B., \& Jenssen, P. D. (2006). Cultural preferences in designing ecological sanitation systems in North West Frontier Province, Pakistan. Journal of Environmental Psychology, 26(3), 236-246. https://doi.org/10.1016/j.jenvp.2006.07.005

O'Keefe, M., Messmer, U., Lüthi, C., \& Tobias, R. (2015). Slum inhabitants' perceptions and decision-making processes related to an innovative sanitation service: Evaluating the Blue Diversion Toilet in Kampala (Uganda). International journal of environmental health research, 25(6), 670-684. https://doi.org/10.1080/09603123.2015.1007842

Pradhan, S. K., Piya, R. C., \& Heinonen-Tanski, H. (2011). Eco-sanitation and its benefits: an experimental demonstration program to raise awareness in central Nepal. Environment, Development and Sustainability, 13(3), 507-518. https://doi.org/10.1007/s10668-010-9273-5

Rajbhandari, K. (2008). Ecological Sanitation Latrines: The Experience of Nepal. Beyond Construction use by All: A Collection of Case Studies from Sanitation and Hygiene Promotion Practitioners in South Asia. In: WaterAid, London. Retrieved from https://www.ircwash.org/sites/default/files/Rajbhandari-2008-Ecological. pdf

Ritchie, J., Lewis, J., Nicholls, C. M., \& Ormston, R. (2013). Qualitative research practice: A guide for social science students and researchers. Sage.

Rogers, E. M. (2010). Diffusion of innovations. Simon and Schuster.

Samwel, M., Gabizon, S., Wolters, A., \& Wolters, M. (2006). From pit latrine to ecological toilet, Results of a survey on dry urine diverting school toilets and pit latrines in Garla Mare. Romania; Experiences and 
Acceptances; WECF, the Netherlands. In: WECF, Utrecht/Munich.

Sene, M., Hijikata, N., Ushijima, K., \& Funamizu, N. (2019). Application of Human Urine in Agriculture. In Resource-Oriented Agro-sanitation Systems (pp. 213-242). Springer. https://doi.org/10.1007/978-4-431-56835-3_15

Sharda, K., \& Shinjo, H. (2017). Effectiveness of ecological sanitation from the viewpoint of urine application on vegetables in central Nepal. Matter: International Journal of Science and Technology, 3(1). https://doi.org/10.20319/Mijst.2017.31.5566

Shonde, W. J. (2016). Application of Ecological Sanitation Approach in Excreta Waste Management Among the Local Community: A Case Study of Hananasif Ward, Kinondoni Municipal. The Open University of Tanzania.

Takahashi, K., Sakai, A., \& Ahmed, T. (2016). The Vulnerability of Toilet Facilities in the Bangladesh Rural Area and Sanitary Improvement by Introduction of the Eco San Toilet. In Coping with Regional Vulnerability (pp. 217-240). Springer. https://doi.org/10.1007/978-4-431-55169-0_12

Trimmer, J. T., Nakyanjo, N., Ssekubugu, R., Sklar, M., Mihelcic, J. R., \& Ergas, S. J. (2016). Assessing the promotion of urine-diverting dry toilets through school-based demonstration facilities in Kalisizo, Uganda. Journal of Water, Sanitation and Hygiene for Development, 6(2), 276-286. https://doi.org/10.2166/washdev.2016.045

Tumwebaze, I., \& Niwagaba, C. (2011). Ecological sanitation uptake, knowledge, beliefs and practices in Kabale Municipality, Kabale District. Paper presented at the CD Proceedings, 35th WEDC International Conference. Retrieved from https://wedc-knowledge.lboro.ac.uk/resources/conference/35/Tumwebaze-I-K1266.pdf

Uddin, S. M. N., Lapegue, J., Gutberlet, J., Adamowski, J. F., Dorea, C. C., \& Sorezo, F. (2019). A Traditional Closed-Loop Sanitation System in a Chronic Emergency: A Qualitative Study from Afghanistan. Water, 11(2), 298. https://doi.org/10.3390/w11020298

Uddin, S., Muhandiki, V., Fukuda, J., Nakamura, M., \& Sakai, A. (2012). Assessment of social acceptance and scope of scaling up urine diversion dehydration toilets in Kenya. Journal of Water, Sanitation and Hygiene for Development, 2(3), 182-189. https://doi.org/10.2166/washdev.2012.078

Werner, C., Panesar, A., Rüd, S., \& Olt, C. (2009). Ecological sanitation: Principles, technologies and project examples for sustainable wastewater and excreta management. Desalination, 248(1-3), 392-401. https://doi.org/10.1016/j.desal.2008.05.080

WHO/UNICEF. (2017). Progress on Drinking Water, Sanitation and Hygiene-Update and SDG Baselines. In: World Health Organization and the United Nations Children's Fund Geneva. Retrieved from https://www.unicef.org/publications/files/Progress_on_Drinking_Water_Sanitation_and_Hygiene_2017.pdf

\section{Notes}

Note 1. NORHED principles to select the schools and research participants are as follows:School should own land for eco-san toilet and school garden (at least 0.5 hectares), have multi-ethnic composition comprising of minority ethnic group and indigenous children, female teachers (at least 3), a large number of students, functional SMC, PTA, and Child-clubs, the facility of electricity and drinking water, and sufficient space/room to develop science and computer laboratory.

Note 2. Drip irrigation is a system of crop irrigation involving the controlled delivery of human urine diluted with water directly to individual plants through pipes.

Note 3. Auto supplying or a piping system means drip irrigation here.

\section{Copyrights}

Copyright for this article is retained by the author(s), with first publication rights granted to the journal.

This is an open-access article distributed under the terms and conditions of the Creative Commons Attribution license (http://creativecommons.org/licenses/by/4.0/). 